Dementia Knowledge Assessment Tool Version Two: Development of a tool to inform preparation for care planning and delivery in families and care staff

\title{
Christine Toye
}

(Curtin Health Innovation Research Institute), Curtin University, Australia

\section{Leanne Lester}

(Faculty of Computing, Health and Science), Edith Cowan University, Australia

\section{Aurora Popescu}

(National Drug Research Institute), Curtin University, Curtin University, Australia

\section{Fran McInerney}

(Faculty of Health Science), Australian Catholic University; Mercy Health, Australia

\section{Sharon Andrews}

(Wicking Dementia Research and Education Centre), University of Tasmania, Australia

\section{Andrew L Robinson}

(Wicking Dementia Research and Education Centre), University of Tasmania, Australia

\section{Corresponding author:}

Christine Toye, School of Nursing \& Midwifery, Curtin University, GPO BOX U1987

Perth, Western Australia 6845.

Email: c.toye@curtin.edu.au 


\section{Acknowledgements}

Expert panel review of the first version of the tool was conducted by educators Sue Dicker, Janice Nockold, Christine Kilmartin, and Kerry Wild. The later expert panel included Professors Mary Fitzgerald and Jenny Abbey, Dr Ursula Kellett, and Ms Wendy Hudson.

Dr Jeremy Drake, Melissa Berg, Katrina Fyfe, and Aurora Popescu (author) were employed to conduct the studies. Dr Jenn Scott has advised regarding future development and testing of the tool and Ms Susan Leggett was involved in piloting Version2. 
Dementia Knowledge Assessment Tool Version Two: Development of a tool to inform preparation for care planning and delivery in families and care staff

\section{Abstract}

Care for the person with dementia requires understanding of the person's perspective and preferences, integrated with knowledge of dementia's trajectory and appropriate care. Version One of the Dementia Knowledge Assessment Tool addressed such knowledge in care workers; Version Two is for families as well as staff. Content validity was established during development. Revisions addressed clarity, time for completion, and reliability. When 671 staff completed Version One before an education intervention, internal consistency reliability estimates exceeded 0.70. Validity was supported by higher scores in professional versus nonprofessional staff and following the education. Version Two was used with 34 family carers and 70 staff members. Internal consistency reliability (Cronbach's alpha coefficient) was promising (0.79, both groups). Completion was within 15 minutes. Median correct responses (from 21) were 14 for families (range 4-20) and 16 for the staff (range 3-21). Eighteen staff members (26\%) and two family carers (6\%) reported substantive dementia education. Inclusion of the person with dementia in care planning is often limited because of a late diagnosis and the progressive impacts of the condition. Establishing a shared staff-family understanding of the dementia trajectory and care strategies likely to be helpful is therefore critical to embarking upon the development and implementation of collaborative long term and end-of-life care plans. Version Two of the Dementia Knowledge Assessment Tool can help establish needs for, and outcomes of, education programs and informational resources in a way that is feasible, minimises burden, and facilitates comparisons across family and staff carer groups. 


\section{Keywords}

Dementia, health knowledge, health services for the aged, questionnaires, reliability and validity 


\section{Introduction}

Inclusion of the 'voice' of the person with dementia in care planning, whenever possible, is mandated (Dupuis et al., 2011). Caring partnerships are also critical. And relationship centred care is promoted as an ideal (Nolan, Davies, Brown, Keady, \& Nolan, 2004). In this approach, therapeutic care involves "a network of relationships" and shared understanding (Nolan et al., p. 52). A shared understanding of care related issues is relevant across the 'triad' of formal and informal care providers and the person with dementia.

The life limiting nature of dementia is indisputable (Sachs, 2009) but the functional and cognitive deterioration that occurs as the condition progresses limits opportunities for the person with dementia to plan for ongoing and end of life care. Obtaining an accurate diagnosis early in the dementia trajectory can also be problematic (lliffe et al., 2012). It is therefore incumbent upon families and care providers to collaborate, planning and delivering appropriate care that is also consistent with the wishes of the person whose health is declining.

Experiences of dementia and care preferences are unique to the individual. Yet there are also broad characteristics of the dementia trajectory that can be anticipated. Also, some care strategies are recognised as helpful to most individuals. Consistent, foundation level, knowledge of the expected dementia trajectory and of appropriate care is therefore required by all those involved in care planning and delivery.

Commensurate with the need for consistent knowledge across care staff, standardised, foundation level, dementia care education was commenced in Australia in 2006, primarily for non-professional aged care workers (Fleming \& 
Fitzgerald, 2009). The Dementia Knowledge Assessment Tool Version One (DKAT1) was developed to measure knowledge change in program participants.

The over-arching purpose of developing the DKAT1 was to provide a reliable, valid, and feasible tool to measure care workers' foundation level knowledge of dementia. After developing and testing this tool, we refined it for use with both staff and families to inform preparation for collaborative care planning. Family input into late stage and end of life care planning has clear potential to help ensure that care is consistent with the perspective of the person with dementia; therefore Version Two (DKAT2) addressed late stage dementia as a priority.

\section{Development of Version One}

The DKAT1 addressed two conceptual domains: 'dementia and its progress' and 'support and care'. Items were initially developed by the first author, a tertiary educator in this topic area. The tool's first draft was reviewed by an expert panel with expertise in educating aged care workers about dementia; they examined content validity, clarity, and apparent internal consistency reliability using a pre-set protocol (Mastaglia, Toye, \& Kristjanson, 2003). The tool's response options were Agree/Disagree/Unsure, collapsed to Correct and Incorrect (Incorrect including Unsure). After refinements from the review, the 33-item draft tool was piloted with care workers attending education. Time taken for completion ranged up to 30 minutes; further revisions resulted to enhance clarity and reduce burden.

To address the draft tool's stability over time, we examined the extent to which responses from 26 care workers were unchanged over from 5 to 14 days with no intervening education. Items eliciting a Kappa (agreement) statistic of 0.40 or less were deleted or revised. Items eliciting correct responses from over $90 \%$ of 
participants were also considered for deletion to minimise potential for a ceiling effect. Cronbach's alpha coefficient for the 25 retained items (Table 1) was 0.67 $(\mathrm{N}=25)$.

\section{Reliability and validity of Version One}

From 2006 to 2008, the DKAT1 was used to evaluate knowledge change from the planned education throughout Western Australia. The education targeted aged care workers, who undertake 'on the job' training and/or competency based aged care training in this country. Smaller numbers of nurses and other staff were also included. Paired (independent) questionnaire responses were collected immediately before the first session (Time One) and at the program's conclusion (Time Two). Findings supported the tool's validity in that the most highly qualified staff members (registered nurses, $n=50$ ) scored significantly better (median=18.2, range=12-24) than care workers $(n=522$, median $=15.0$, range $=0-24)$ at Time One $(z=-5.60$, $\mathrm{p}<0.001$ ). Overall, the median (total correct) score before the education was 16 (range $=0-24), 20$ afterwards (range $=9-25)$, a significant improvement $(z=21.09$, $\mathrm{p}<0.001, \mathrm{~N}=671$ ). Percentages of correct responses improved for every question. Cronbach's alpha coefficient for Time One was $0.72(\mathrm{~N}=613)$; at Time Two it was $0.64(\mathrm{~N}=615)$.

\section{Development of Version Two}

In 2009/10, we drafted the D-KAT2. Review was by four experts who were aware of the content of the DKAT1 and the purpose of refinement; their expertise was in supporting families of people with dementia, education and research in this area, and tool development. Review and refinement processes mirrored those for Version One. Piloting was in three residential aged care settings, with family carers, aged care 
workers, and nurses who provided support for residents with dementia. Residents needed to have suspected or diagnosed dementia and to meet criteria for moderate to very severe cognitive decline (Reisberg, 1988).

The first draft of the DKAT2 comprised 25 items, 11 of which were new; after review there were 21 and response options were Yes/No/Unsure. After piloting with 30 family carers (10 daughters, 10 spouses, 10 others) and 30 staff ( 7 registered nurses, 5 enrolled nurses, 18 care workers), Cronbach's alpha coefficient was 0.67 $(n=25)$ for staff, $0.69(n=27)$ for families. Participants took 3 to 15 minutes for completion. No items were found to be unclear but the 'Unsure' response option was changed to 'Don't Know' to support clarity.

\section{Reliability and validity of Version Two}

In four more residential aged care settings, all contactable workers providing care for residents with dementia were invited to participate, as were all family members involved in the care or support of residents with dementia for at least 3 months. Residents had a suspected or diagnosed dementia and a Cognitive Decline Scale score (Jorm \& Mackinnon, 1995) consistent with moderately severe to very severe cognitive decline (Reisberg, 1988).

Thirty four family carers (28\% of those approached) completed the DKAT2; $20(59 \%)$ were sons or daughters, and $23(68 \%)$ were aged at least 55 years. Family carers' dementia related learning was primarily from caring for family, although two participants $(6 \%)$ had attended a relevant program or course and one $(3 \%)$ had attended a seminar or talk. The median number of correct responses was 14 (range 4-20); Cronbach's alpha coefficient was $0.79(n=33)$. Four items received a correct 
response from at least $90 \%$ of family participants and six an incorrect response from at least $50 \%$ (Table 2 ).

Seventy staff members (95\% of those approached) also completed the DKAT2; 33 (47\%) were older than 45 years, 54 (77\%) were care workers, and $27(39 \%)$ had worked in aged care for less than 2 years. There were 9 registered nurses (13\%) and 7 enrolled nurses (10\%). Eighteen (26\%) of the staff reported attending dementia education programs or courses with a further 27 (44\%) attending seminars or talks. A median of 16 questions were answered correctly (range 3-21) and Cronbach's alpha coefficient was again $0.79(n=59)$. Seven items received a correct response from at least $90 \%$ of staff and two an incorrect response from at least $50 \%$ (Table 2).

\section{Discussion}

The DKAT1 was developed to evaluate foundation level knowledge of the dementia trajectory and care in care workers; it has now been modified to provide the DKAT2. The new tool evaluates the same kind of knowledge as the DKAT1, but in family carers and aged care staff and with a greater emphasis on late stage dementia. Correct scores can be totalled to provide an indication of overall knowledge and the tool is feasible for use in aged care environments. Preliminary testing provides promising internal consistency reliability estimates and content validity has been established by experts. Findings from testing with a small sample provide further initial support for the tool's validity in that the staff obtained marginally higher scores than families, also reporting (a little) more formal education in this area. Revisions will become essential as knowledge changes; further refinements may also result from future validity and reliability testing and to limit ceiling effects from items 
consistently attracting a high percentage of correct scores in both families and the staff. Nonetheless, DKAT2 fills a gap in existing resources because it helps to evaluate knowledge of dementia and dementia care, rather than of any specific dementia related illness (eg, Alzheimer's disease), making the tool more broadly applicable. Also, the tool presents as a quiz; it is not onerous to complete but provides some clear indications of misunderstandings that may have occurred or where knowledge is simply lacking.

Establishing a shared understanding of the dementia trajectory is critical to embarking upon the development of long term and end-of-life care plans and to the provision of collaborative care. Whereas inclusion in care planning of the person with dementia is the ideal, opportunities for this reduce as the condition progresses. Ensuring that the staff-family nexus is based upon accurate and consistent understanding is a priority. The DKAT2 can help establish needs for, and outcomes of, education programs and informational resources in a way that is feasible, minimises burden, and facilitates comparisons across family and staff carer groups.

\section{Conflict of Interest}

The authors declare that there is no conflict of interest. 


\section{References}

Fleming, R., \& Fitzgerald, D. (2009). Large-scale training in the essentials of dementia care in Australia: Dementia Care Skills for Aged Care Workers project. International Psychogeriatrics, 21(Supplement 1), S53-S57.

lliffe, S., Koch, T., Jain, P., Lefford, F., Wilcock, J., Wong, G., \& Warner, A. (2012).

Developing an educational intervention on dementia diagnosis and management in primary care for the EVIDEM-ED trial. Trials, 13(1), 142.

Jorm, A., \& Mackinnon, A. (1995). The Psychogeriatric Assessment Scales.

Canberra, ACT, Australia: NHMRC Social Psychiatry Research Unit, Mental Health Research Institute, Australian National University,.

Mastaglia, B., Toye, C., \& Kristjanson, L. J. (2003). Ensuring content validity in instrument development: Challenges and innovative approached. Contemporary Nurse, 14(3), 281-291.

Nolan, M. R., Davies, S., Brown, J., Keady, J., \& Nolan, J. (2004). Beyond 'personcentred' care: a new vision for gerontological nursing. Journal of Clinical Nursing, 13, 45-53. doi: 10.1111/j.1365-2702.2004.00926.x

Reisberg, B. (1988). Functional assessment staging (FAST). Psychopharmacology Bulletin, 24, 653-659.

Sachs, G. A. (2009). Dying from Dementia. New England Journal of Medicine, 361(16), 1595-1596. doi: doi:10.1056/NEJMe0905988 


\section{Table 1}

\section{Abbreviated items in Version 1}

Correct statements

Dementia because of changes in the brain.

Alzheimer's disease main cause.

Dementia a collection of symptoms.

Treatments can make a difference.

Difficulty following story lines sometimes a sign.

Approximately 1\% aged 60-69 has dementia.

Exercise can be beneficial.

Agitation may mean rest is needed.

Can talk about feelings to distract.

Can generally be supported to make choices.

Help line available.

Difficulties with spatial awareness common.

Incorrect statements

Only older adults develop dementia.

People never have vascular dementia and Alzheimer's.

Anti-social behaviour only occurs when usual.

Incontinence an early sign. 
Confusion in older person almost always due to.

Diagnosed quickly by a doctor.

Knowing diagnosis means length of illness known.

Most people live in residential care.

Better off not knowing.

Changing environment makes no difference.

Essential to sleep through night.

Reality orientation always appropriate.

Validation therapy aims to orientate. 
Table 2

Percentage of correct responses to Version 2 items

Abbreviated Item $\quad$ staff $(n=70) \quad$ families $(n=34)$

Correct statements

Dementia because of changes in the brain.

Brain changes often progressive.

Alzheimer's disease main cause.

Blood vessel disease can cause.

Families can help understand needs.

May develop problems with visual perception.

May help to talk about feelings.

Can often be supported to make choices.

Incorrect statements

Confusion in older person almost always due to. $\quad 78$ 
Knowing likely cause helps to predict.

Incontinence always in the early stages.

65

Sudden increases in confusion characteristic.

19

06

Changing environment makes no difference.

62

53

Important to always correct.

69

88

Impossible to tell if in pain.

70

44 
Here are some statements about dementia.

Please read each statement carefully and place a tick in the box to show if you agree or disagree with the statement, or if you don't know.

It is important to tick only one box (yes, no, or don't know) for every statement.

\begin{tabular}{|c|c|c|c|}
\hline & Yes & No & $\begin{array}{l}\text { Don't } \\
\text { know }\end{array}$ \\
\hline 1. Dementia occurs because of changes in the brain. & & & \\
\hline $\begin{array}{l}\text { 2. Brain changes causing dementia are often } \\
\text { progressive. }\end{array}$ & & & \\
\hline 3. Alzheimer's disease is the main cause of dementia. & & & \\
\hline 4. Blood vessel disease can also cause dementia. & & & \\
\hline $\begin{array}{l}\text { 5. Confusion in an older person is almost always due to } \\
\text { dementia. }\end{array}$ & & & \\
\hline 6. Only older adults develop dementia. & & & \\
\hline $\begin{array}{l}\text { 7. Knowing the likely cause of dementia can help to } \\
\text { predict its progression. }\end{array}$ & & & \\
\hline $\begin{array}{l}\text { 8. Incontinence always occurs in the early stages of } \\
\text { dementia. }\end{array}$ & & & \\
\hline 9. Dementia is likely to limit life expectancy. & & & \\
\hline $\begin{array}{l}\text { 10. When a person has late stage dementia, families can } \\
\text { help others to understand that person's needs. }\end{array}$ & & & \\
\hline $\begin{array}{l}\text { 11. People who have dementia may develop problems } \\
\text { with visual perception (understanding or recognising } \\
\text { what they see). }\end{array}$ & & & \\
\hline $\begin{array}{l}\text { 12. Sudden increases in confusion are characteristic of } \\
\text { dementia. }\end{array}$ & & & \\
\hline
\end{tabular}


Here are some statements about dementia.

Please read each statement carefully and place a tick in the box to show if you agree or disagree with the statement, or if you don't know.

It is important to tick only one box (yes, no, or don't know) for every statement.

\begin{tabular}{|c|c|c|c|}
\hline & Yes & No & $\begin{array}{l}\text { Don't } \\
\text { know }\end{array}$ \\
\hline $\begin{array}{l}\text { 13. Uncharacteristic distressing behaviours may occur in } \\
\text { people who have dementia (e.g., aggressive } \\
\text { behaviour in a gentle person). }\end{array}$ & & & \\
\hline 14. Difficulty swallowing occurs in late stage dementia. & & & \\
\hline $\begin{array}{l}\text { 15. Movement (e.g., walking, moving in a bed or chair) is } \\
\text { limited in late stage dementia. }\end{array}$ & & & \\
\hline $\begin{array}{l}\text { 16. Changing the environment (e.g., putting on a CD, } \\
\text { opening or closing the blinds) will make no } \\
\text { difference to a person who has dementia. }\end{array}$ & & & \\
\hline $\begin{array}{l}\text { 17. When a person who has dementia is distressed, it } \\
\text { may help to talk to them about their feelings. }\end{array}$ & & & \\
\hline $\begin{array}{l}\text { 18. It is important to always correct a person who has } \\
\text { dementia when they are confused. }\end{array}$ & & & \\
\hline $\begin{array}{l}\text { 19. A person who has dementia can often be supported } \\
\text { to make choices (e.g., what clothes to wear). }\end{array}$ & & & \\
\hline $\begin{array}{l}\text { 20. It is impossible to tell if a person who is in the later } \\
\text { stages of dementia is in pain. }\end{array}$ & & & \\
\hline $\begin{array}{l}\text { 21. Exercise can sometimes be of benefit to people who } \\
\text { have dementia. }\end{array}$ & & & \\
\hline
\end{tabular}

The Dementia Knowledge Assessment Tool Version 2 was developed from Version 1 at Curtin University, Edith Cowan University, the Australian Catholic University, and the University of Tasmania by Toye, C., Lester, L., Popescu, A., Mclnerney, F., Andrews, S., and Robinson, A. L. Version 1 was developed at Edith Cowan University with funding from the Australian Government Department of Health and Ageing and support from a dementia education consortium led by Alzheimer's Australia WA.

This document may be reproduced with this acknowledgement retained. 